\title{
Radiation Crosslinking of Polyurethanes: Characterization by FTIR, TGA, SEM, XRD, and Raman Spectroscopy
}

\author{
Mohamed Mohamady Ghobashy ${ }^{1}$ and Zizi I. Abdeen ${ }^{2}$ \\ ${ }^{1}$ Radiation Research of Polymer Department, National Center for Radiation Research and Technology (NCRRT), \\ Atomic Energy Authority, P.O. Box. 29, Nasr City, Cairo, Egypt \\ ${ }^{2}$ Polymers Laboratory Petrochemicals Department, Egyptian Petroleum Research Institute (EPRI), P.O. Box. 11727, Cairo, Egypt
}

Correspondence should be addressed to Mohamed Mohamady Ghobashy; mohamed.ghobashy@eaea.org.eg

Received 7 June 2016; Revised 17 September 2016; Accepted 5 October 2016

Academic Editor: Raghu V. Anjanapura

Copyright (C) 2016 M. M. Ghobashy and Z. I. Abdeen. This is an open access article distributed under the Creative Commons Attribution License, which permits unrestricted use, distribution, and reproduction in any medium, provided the original work is properly cited.

\begin{abstract}
Gamma radiation can be used for enhancing the physical properties of polyurethane (PU). Radiation was used to crosslink a polyurethane at room temperature; four samples of the PU solid film are irradiated at variable four radiation doses $0,50,100$, and $150 \mathrm{kGy}$ under vacuum conditions. Crosslinking radiation is more common than oxidative degradation and crosslinking is believed to be more efficient in the soft segment of PU. The structure of the PUs is performed by Fourier transform infrared (FTIR-ATR), Thermogravimetric Analysis (TGA-DTG), and X-ray Diffraction (XRD) which have been used to investigate the effect of gamma radiation on the polyurethane (PU). The results showed that the radiation crosslinking of polyurethanes improved the thermal stability and the crystallinity. The microstructure modifications of polyurethane samples have also been studied as a function of the dose using the scanning electron microscope (SEM). The effects of gamma irradiation on the color changes of polyurethane were observed. The irradiated PUs have conjugated structure and are capable of emitting purple fluorescence.
\end{abstract}

\section{Introduction}

Polyurethanes are produced by reacting an isocyanate $(\mathrm{N}=\mathrm{C}=\mathrm{O})_{n}$ with a polyol containing on average two or more hydroxyl groups per molecule $(\mathrm{OH})_{n}$. The aromatic isocyanates, diphenylmethane diisocyanate (MDI), or toluene diisocyanate (TDI) are more reactive than aliphatic isocyanates, such as hexamethylene diisocyanate (HDI) or isophorone diisocyanate (IPDI). An important exception to this is diphenylmethane diisocyanate [1].

Polyurethane elastomers are an important type of polymer material with excellent physical and chemical properties. And, many applications have been found in different fields. There are further studies about polyurethane elastomers with graded structure. Raghu and coworkers [2-6] reported the synthesis and characterization of novel linear segmented polyurethanes (PUs) containing Schiff base, chalcone, and azo-based diols like 4,4' ${ }^{\prime}$-(ethane-1,2-diylidenedinitrilo)diphenol, $4,4^{\prime}$ - (pentane-1,5-diylidenedinitrilo)diphenol, $2,2^{\prime}$-[1,4-phenylenebis(nitrilomethylylidene)]diphenol, 2,2'-[4,4'-methylene-di-2-methylphenylene- $1,1^{\prime}$ bis(nitrilomethylylidene)]diphenol, 4-[[(4-hydroxyphenyl)imino]methyl]phenol, 2,6-bis(4-hydroxybenzylidene)cyclohexanone, $4,4^{\prime}$-[1,4-phenylenedi-diazene-2,1-diyl]bis(2carboxyphenol), and $4,4^{\prime}$ - - henylenedi-diazene-2,1-diyl]bis(2chlorophenol) with various diisocyanates [2, 3, 7-9]. And they successes to introduce a dihydrazide diol moiety in the main chain like $\mathrm{N}_{1}, \mathrm{~N}_{2}$-bis[(4-hydroxyphenyl)methylene] ethanedihydrazide (BHPMED) with 4,4'-diphenylmethane diisocyanate (MDI), tolylene 2,4-diisocyanate (TDI), isophorone diisocyanate (IPDI), and hexamethylene diisocyanate (HDI) [3]. Jeong et al. 2003 [4] prepared nanocomposite of waterborne polyurethane (WPU) based on poly(hexamethylene carbonate) diol reinforced by 
organophilic clay. They observed the water swell was decreased and thermal resistance was increased as the content of clay was increased. Reinforcement of polyurethane by composite with inorganic materials has attracted considerable attention in various literature because they exhibit the enhanced performance properties compared with conventional composites. Choi et al. 2012 [5] prepared nanocomposites of waterborne polyurethane (WPU) reinforced with functionalized graphene sheets (FGSs). Reddy and coworkers, prepared a series of novel segmented polyurethanes (PUs) containing imine units by polyaddition reaction of various diisocyanates like $4,4^{\prime}$-diphenyl-methane diisocyanate (MDI), toluene 2,4-diisocyanate (TDI), isophorone diisocyanate (IDI), and hexamethylene diisocyanate (HDI) with 4,4'-[1,4-phenylenebis(methylylidenenitrilo)] diphenol based diol [6], with 4,4' ${ }^{\prime}$-\{pyridine-2,6-diylbis[nitrilomethylylidene] \}diphenol-based diol [10].

Radiation crosslinking polymerization is one of the important research fields of radiation polymerization [11]; radiation crosslinking modification of polyurethanes is one of most important aspects [12]. In the study of the radiation crosslinking polyurethane, a lot of work was done in polyurethane synthesis, in its molecular backbone to import some unsaturated bond and application of $\gamma$-irradiation to realize the radiation crosslinking in order to obtain a better crosslinking effects, improved thermal stability, and other properties of polyurethane. In another study on the influence of electron-beam irradiation in air on the chemical and the structural properties of medical-grade polyurethane, the results show homogeneous oxidative degradation followed by a decrease in molecular mass and an increase in polydispersity [13]. The chain scission is common by the irradiation UV and gamma irradiation in air of polyurethane [14]. In this paper we irradiated polyurethane film in isolated of air under vacuum conditions. Segmented (soft and hard) polyurethanes (PUs) are a class of thermoplastic elastomers that bridge the gap between rubbers and plastics and could be influenced by irradiation [15]. The superior properties of PUs originate in the thermodynamic incompatibility between the hard segments (HSs) and soft segments (SSs). When PUs are exposed to high energy irradiation, the structure and mechanical property may be altered. It is of importance from both basic and applied viewpoints to determine how the microstructure and stability could be influenced by irradiation. Generally, PUs have shown higher radiation resistance compared with other common polymers, such as polyolefins and vinyl polymers [16]. However, the effects of irradiation on the microstructure are complex and closely related to the chemical composition, irradiation environment, and absorbed dose [17].

In this paper, radiation was used in crosslinking of polyurethane at room temperature under vacuum of air. The radiation crosslinking affects the characterization of polyurethane like morphology of microstructure as detected by SEM and thermal stability enhancing with irradiation dose beside the crystanility, as observed from TGA and XRD data. The irradiated PU emits purple fluorescence light when exposed to UV lamp $(362 \mathrm{~nm})$.

\section{Materials and Method}

A commercial 4,4'-diphenylmethane diisocyanate (MDI) from the market and polyether were obtained from commercial suppliers. The MDI and polyether were used as received. Toluene was obtained from Sigma-Aldrich Chemical Co.

2.1. Preparation of Polyurethane. The synthesis procedure was carried out on the basis of prepolymer method. A weighed quantity of dried $102.9 \mathrm{~g}$ of polyether polyol was mixed well with $150 \mathrm{~mL}$ toluene and charged into a four-necked flask and equipped with stirrer, thermometer, dropping funnel, gas inlet, and air condenser with a drying tube. During flushing with a slow stream of nitrogen the mixture was heated at temperature of $55 \pm 5^{\circ} \mathrm{C}$ and stirred. Then $40 \mathrm{~mL}$ of 4,4 diphenylmethane diisocyanate (MDI) was dropped into the mixture gradually over a period of $30 \mathrm{~min}$. With continuous stirring at the end of the reaction (after 6-8h), the final product was a clear yellowish viscous liquid. Isocyanate terminated polyurethane prepolymer was formed after casting step.

2.2. Polyurethane Film Preparation. For the preparation of the polyurethane film, the liquid purified prepolymer was cast onto the surface of a glass plate and then left to be cured under ambient conditions. A combination of above reactions occurred due to the simultaneous presence of polyol in the reaction system. Finally, prepolymer chains completely react with an equivalent amount of water, leading to the formation of crosslinked polyurethane. Then films were dried at variable temperatures ranging from $30^{\circ} \mathrm{C}$ to $40^{\circ} \mathrm{C}$ for $24 \mathrm{~h}$ to ensure slow drying in order to completely remove the solvent. Subsequently, the films were removed from the mold and stored in a desiccator at room temperature for further characterization.

2.3. Irradiation Conditions. Irradiate the samples at doses of $0,50,100$, and $150 \mathrm{kGy}$ with the 60 Co Indian irradiation facility gamma rays at a dose rate $2.05 \mathrm{KGy} / \mathrm{h}$. All samples were irradiated at room temperature in the absent of air. The irradiation facility was constructed by the National Center for Radiation Research and Technology (NCRRT), Atomic Energy Authority of Egypt (AEAE), Cairo.

\section{Characterizations of the Samples}

3.1. (ATR/FTIR)/Raman Spectroscopy. The probability of prepolymerization method with isocyanate/polyol group $([\mathrm{N}=\mathrm{C}=\mathrm{O} / \sim \mathrm{O}-\mathrm{H}])$ was measured using attenuated total reflectance-Fourier transform infrared ATR-FTIR spectroscopy Vertex 70 FTIR spectrometer equipped with HYPERION $^{\mathrm{TM}}$ series microscope, Bruker Optik GmbH, Ettlingen, Germany, over the $4000-400 \mathrm{~cm}^{-1}$ range, at a resolution of $4 \mathrm{~cm}^{-1}$. Software OPUS 6.0 (BRUKER) was used for data processing, which was baseline corrected by the rubber band method with $\mathrm{CO}_{2}$ bands excluded. The Raman measurement was carried out with dispersive Raman spectroscopy at laser $785 \mathrm{~nm}$ and laser power 0.10 MW, Senterra, Bruker Optics, Germany. 
3.2. $X R D$. The effects of gamma radiation at the crystallinity of polyurethane samples were measured using X-ray diffraction patterns which were obtained using XRD-6000 series. Polymer blend samples were analysed via overlaid X-ray diffraction patterns by Shimadzu apparatus using nickelfilter, $\mathrm{Cu}-\mathrm{K}$ target, voltage $=40(\mathrm{kV})$, current $=30(\mathrm{~mA})$, and scan speed $=8(\mathrm{deg} / \mathrm{min})($ Shimadzu Scientific Instruments (SSI), Kyoto, Japan).

3.3. SEM. The surface morphology and the formation of crystalline regions of irradiated polyurethane films were performed using scanning electron microscopy (SEM) with the working operation at $20 \mathrm{kV}$ (JEOL JSM-5400, Jeol Ltd., Tokyo, Japan). All samples coated with a thin layer of gold. Images of these samples were taken using optical microscope with 200x magnifications.

3.4. TGA/DTG. Thermal analysis was performed using TGA from (TA Instruments, New Castle, DE, USA). The TGA features a top-loading balance. Furnaces provide the highest available cooling speed and conversely, they are heated up to $500^{\circ} \mathrm{C}$ with heating rate $10^{\circ} \mathrm{C} / \mathrm{min}$.

\section{Results and Discussion}

4.1. FTIR and Raman Spectroscopy of Irradiated Polyurethane. The polyurethane (PU) was synthesized by prepolymerization method with isocyanate/polyol group $([\mathrm{NCO} / \mathrm{OH}])$ in ambient temperature and exposed the obtained solid film to gamma irradiation at various doses from 0 up to $150 \mathrm{kGy}$. The presence of the urethane bond was observed in all the FTIR spectra (Figure 1(a)-(d)) of the irradiated and unirradiated PU. The carbonyl peak was identified at $1718 \mathrm{~cm}^{-1}$ in all curves (a) to (d) while the disappearance of isocyanate peak (-NCO) was observed around $2270 \mathrm{~cm}^{-1}$ and hydroxyl (no peak at $3456 \mathrm{~cm}^{-1}$ ), indicating a complete usage of all isocyanates present in the prepolymer reactants $[18,19]$ and the excess of $\mathrm{OH}$ favors crosslinking yielding of the rigid PU [20]. The FTIR spectroscopy analysis justified that the diisocyanate was the main contributor in the formation of the hard segment of the PU. The two bands observed between 2930 and $2840 \mathrm{~cm}^{-1}$ were attributed to symmetric and nonsymmetric stretching of the $\mathrm{C}-\mathrm{H}$ bond [21]. When the gamma irradiation increased, the formation of hard segment of PU will be affected and show nonhydrogen bonding in structures of unirradiated and irradiated PU due to disappearing peaks between 1643 and $1675 \mathrm{~cm}^{-1}$ because of the presence of hydrogen bonded $\mathrm{C}=\mathrm{O}$ group $[22,23]$. The imine bands $(\mathrm{CH}=\mathrm{N})$ have appeared at $1601 \mathrm{~cm}^{-1}$ [24]. Hence, irradiated PU may have stronger bonds due to gamma doses than bonds of unirradiated PU sample.

Raman spectroscopy, which is a complementary technique to infrared spectroscopy, also measures the vibrational energy levels. In Figures 2(a)-2(d) are the asymmetric and symmetric stretching vibrations of irradiated and unirradiated PU. Both the isocyanate asymmetric stretch at $2275 \mathrm{~cm}^{-1}$ and symmetric stretch at $1445 \mathrm{~cm}^{-1}$ disappeared with polymerization process taking place. The ether link (C-O-C) was found at $1182 \mathrm{~cm}^{-1}$ which is composed of a large set

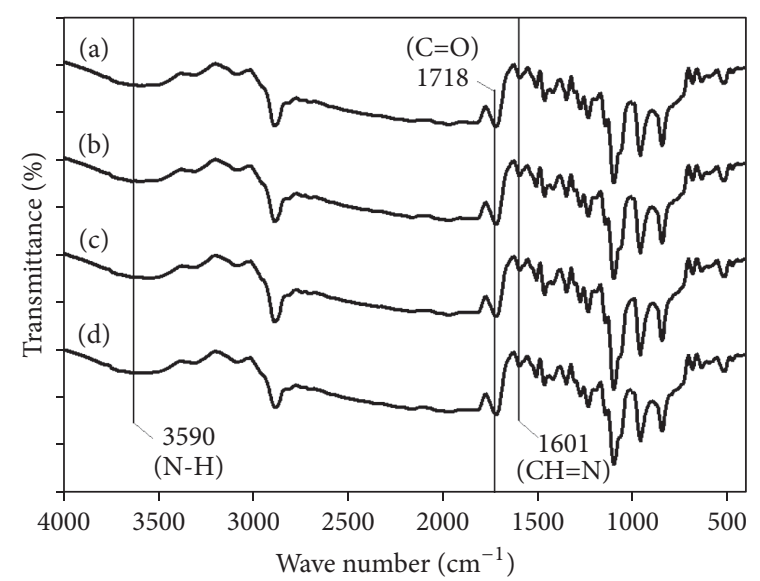

FIGURE 1: FTIR-ATR chart for irradiated PU with (a) $0 \mathrm{kGy}$, (b) $50 \mathrm{kGy}$, (c) $100 \mathrm{kGy}$, and (d) $150 \mathrm{kGy}$.

of polyol within the isocyanate. The aromatic ring showed chemical bands characteristic of the molecular structure of polyurethanes, such as the Raman bands corresponding to the urethane $(\mathrm{N}-\mathrm{H})$ amid II group $\left(1532 \mathrm{~cm}^{-1}\right)$ and to phenol group $\left(1613 \mathrm{~cm}^{-1}\right)$. These bands were the result of aromatic ring breathing/stretching vibrational modes present in the phenylene groups of MDI [25]. Additionally, peaks at 678, 746 , and $880 \mathrm{~cm}^{-1}$ characteristic of C-C bonds were found in an aromatic conformation [26].

4.2. Effect of Irradiation Doses on the Crystallinity of Crosslinked Polyurethane. We are using X-ray diffraction to investigate the effect of gamma irradiations on the structure of polyurethane elastomers [27], concentrating on the hard segments in diphenylmethane diisocyanate (MDI) and soft segment as polyether. Polyurethane block copolymers derive their elastomeric properties from phase separation into hard (polyurethane) and soft (polyether) domains.

X-ray diffracts for irradiated samples and the original unirradiated (PU) were shown in Figure 3. The curves for irradiated samples were translated for higher intensity values. The increase of crystallinity of the PU samples is evidenced mainly by the appearance of the two characteristic peaks located at $2 \theta=19^{\circ}$ and $23^{\circ}$.

The intensity of this peak increased with radiation doses being increased. Also X-ray diffraction curves indicate a decrease in $d$-spacing $(\AA)$ corresponding to a lower distance between aromatic rings from MDI [14], where for PU (0 kGy) the $2 \theta=19.05^{\circ}(4.653 \AA)$ and $23.28^{\circ}(3.817 \AA)$, for PU (50 kGy) $2 \theta=19.25^{\circ}(4.606 \AA)$ and $23.28^{\circ}$ (3.790 $\AA$ ), for PU (100 kGy) $2 \theta=19.27^{\circ}(4.600 \AA)$ and $23.28^{\circ}(3.793 \AA)$, and for PU ( $150 \mathrm{kGy}) 2 \theta=19.42^{\circ}(4.565 \AA)$ and $23.58^{\circ}(3.769 \AA)$. According to Trovati et al. [28] and Yang [29] the peak at $19^{\circ}$ corresponds to regular interplanar spacing corresponding to aromatic rings from hard segment of MDI. A right shift in the position of the peak at $19^{\circ}$ indicates a decrease in the chain spacing. These effects indicate an increase in the crosslink that promotes decrease in $d$-spacing $(\AA)$ and right shift of the peak at $19^{\circ}$. These results showed that the degree of crystallinity 


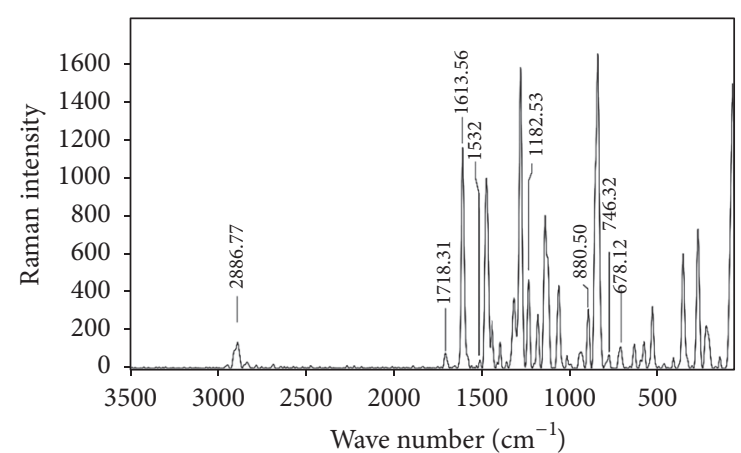

(a)

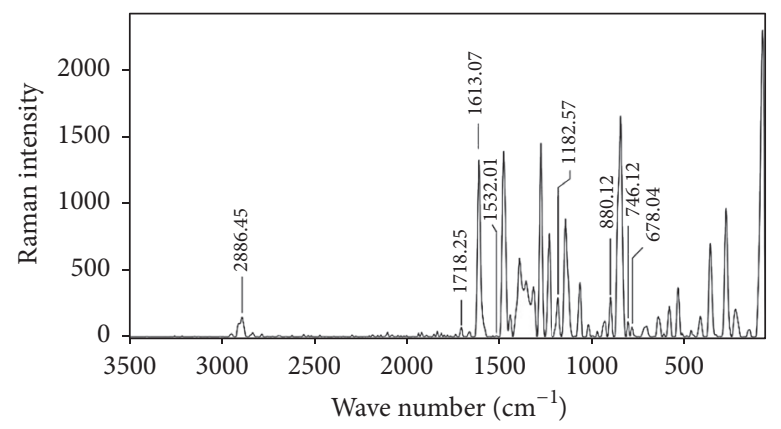

(c)

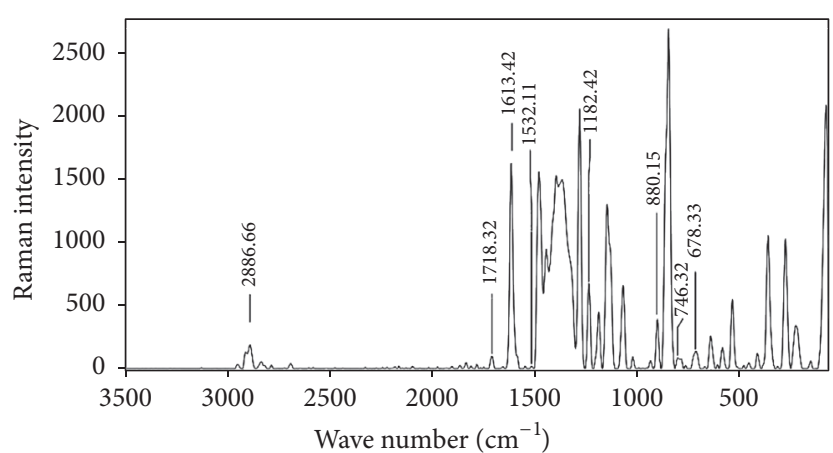

(b)

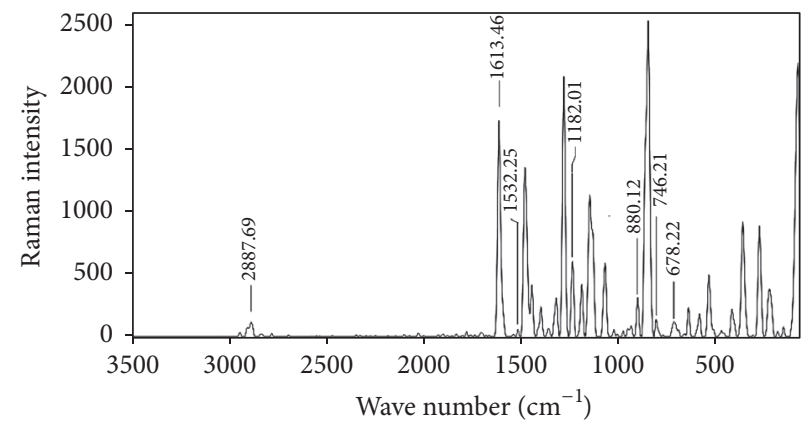

(d)

FIGURE 2: Raman spectroscopy for irradiated PU with (a) 0 kGy, (b) $50 \mathrm{kGy}$, (c) $100 \mathrm{kGy}$, and (d) $150 \mathrm{kGy}$.

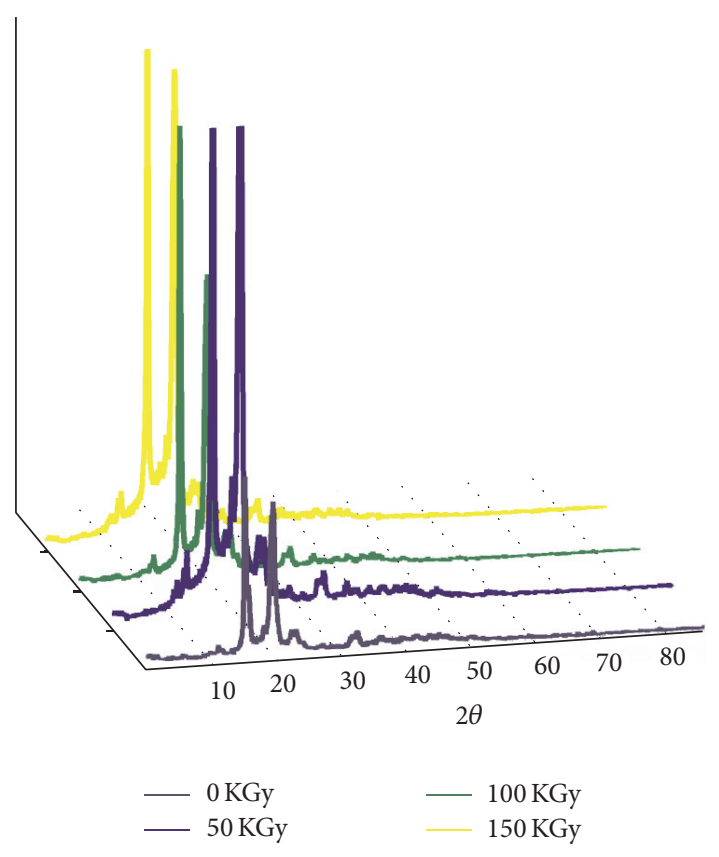

FIGURE 3: X-ray diffraction of irradiated polyurethane.

is controlled by the gamma irradiation doses. The change of crystallinity can be explained by the degree of crosslinking of the PU samples.

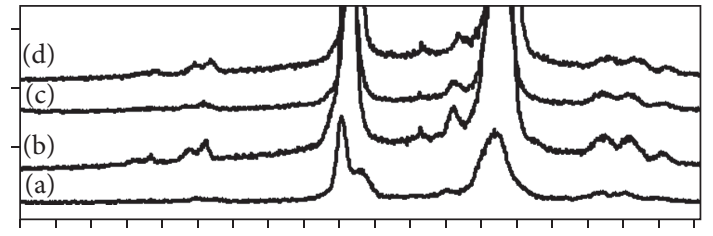

1011121314151617181920212223242526272829

$2 \theta$

FIGURE 4: X-ray diffraction of irradiated polyurethane (a) $0 \mathrm{kGy}$, (b) $50 \mathrm{kGy}$, (c) $100 \mathrm{kGy}$, and (d) $150 \mathrm{kGy}$.

As mentioned, highly ordered crystalline structure depends on the absorbed gamma radiation by the polyurethane backbone. The X-ray diffraction in Figures 4(a)$4(\mathrm{~d})$ showed that the increase in gamma irradiation doses results in increase in the intensity of the peak attributed to soft segment localized at $2 \theta=21.35^{\circ}$ and this confirms that soft segment tends to crystallize generating better defined peak not observed for unirradiated PU [30,31]. This indicates that the crystallinity of PU elastomers is provided by the soft segments. As shown in Figure 4 the intensity of peak at $2 \theta=21.35^{\circ}$ increased with irradiation doses being increased, which relates to a certain degree of structural ordering upon irradiation Therefore, the XRD results imply that the ordered of soft segment is increased induced by crosslinking [17]. And the part of the PUs structure due to the hard segments would be less crystalline than the soft segments, which are able to crosslink by gamma radiation and give a structure as 
crystalline as possible. These results confirm the hypothesis that the radiation crosslink of polyurethane increases in the soft segment rather than hard segment. This increase in the orientation degree and higher intensity of crystallinity in the irradiated PU is due to radiation crosslinked process. Hence crosslinking like hydrogen bonding still influenced the crystallization process of the PU samples [32].

Corresponding to Figures 4(b)-4(d), there are seven diffraction peaks within $2 \theta=13.7^{\circ}, 14.8^{\circ}, 15.29^{\circ}, 22.4^{\circ}, 26.3^{\circ}$, $27.1^{\circ}$, and $28.1^{\circ}$ which are observed for all the irradiated PU samples. The only observed five diffraction peaks in the unirradiated PU samples as shown in Figure 4(a) localized with low intensity at $2 \theta=14.8^{\circ}, 22.4^{\circ}, 26.3^{\circ}, 27.1^{\circ}$, and $28.1^{\circ}$. This indicates that the crosslinked bonds induced by gamma irradiations did not lie in one plane.

\subsection{Effect of Irradiation Doses on the Morphological Micro-} structure of Crosslinked Polyurethane. The morphological microstructure of the irradiated and unirradiated PU is characterized with SEM image. The level of crosslinking and crystallinity of unirradiated and irradiated PU surfaces are shown in Figures 5(a)-5(d). SEM image shows crystalline inclusions obtained after gamma irradiation at doses 50, 100, and $150 \mathrm{kGy}$. All the irradiated samples show crystallinity regions rather than amorphous regions by lines formation in the union direction. The surface shows some roughness region as shown in Figure 5(a) while it involves the effect of gamma radiation. The crystalline region becomes predomain as shown in Figures 5(b)-5(d). The cross-section SEM image in Figures $5\left(\mathrm{a}^{\prime}\right)-5\left(\mathrm{~d}^{\prime}\right)$ shows the increase of radiation dose leading to an increase in the crosslinking induced by gamma radiation.

Solid PU films under irradiation with a general visible and UV lamp ( $\lambda=365 \mathrm{~nm}$ ), of the polyurethane before and after (Figure 6 curve I(a)-(d)) gamma irradiation treatment, indicate that the polyurethane acquires color change under gamma irradiation. The polyurethane was only turned to yellow after being irradiated in absence of oxygen under vacuum conditions, while those exposed to UV radiation $(365 \mathrm{~nm})$ exhibited strong UV absorption and gave purple color that increased with gamma radiation doses increased from 0 up to $150 \mathrm{kGy}$ (Figure 6 curve $\operatorname{II}\left(\mathrm{a}^{\prime}\right)-\left(\mathrm{d}^{\prime}\right)$ ) illustrating the purple color of solid PU films. It can be explained by the $\pi-\pi^{*}$ transitions resulting from charge transfer between nitrogen atoms from PU units and the bisphenol rings with the electron-donating of methyl $\left(-\mathrm{CH}_{3}\right)$ substituent in the bisphenol of PU [33]. This indicated that the irradiated PUs have conjugated structure and are capable of emitting fluorescence light.

The light photomicrographs (mag. 200x) of the polyurethane before and after (Figure 6 curve $\operatorname{III}\left(\mathrm{a}^{\prime \prime}\right)-\left(\mathrm{d}^{\prime \prime}\right)$ ) gamma irradiation treatment indicate that the polyurethane acquires color changes under gamma where it turns to yellow after irradiated in absence of oxygen under vacuum. While if the color of PU turned dark brown it is a probable oxidation of the amine and this indicates the degradation of PU in presence of oxygen $[34,35]$. The difference in color combined with change in the degree of crosslinking and crystallinity was observed. This indicated significantly the influence of gamma irradiation.

4.4. Effect of Irradiation Doses on the Thermal Stability of Crosslinked Polyurethane. All samples of irradiated and unirradiated polyurethane thermally coincide until temperature $298^{\circ} \mathrm{C}$, where TGA data indicate that the MDI-based PUs exhibited better thermal stability and this is attributed to the presence of biphenyl groups on the main chains [36]. Some difference was observed between 333 and $480^{\circ} \mathrm{C}$ as shown in Figure 7 where the thermal stability of radiation crosslinking polyurethane is greatly improved. The temperatures of $20 \%$ weight loss for polyurethane irradiated by 50,100 , and $150 \mathrm{kGy}$ are $393.20^{\circ} \mathrm{C}, 384.6^{\circ} \mathrm{C}$, and $379.5^{\circ} \mathrm{C}$, respectively, but the temperature of $20 \%$ weight loss of unirradiated polyurethane is only $376.13^{\circ} \mathrm{C}$. This indicated that at $50 \mathrm{kGy}$ the polyurethane is highly thermally stability than the other doses. Also, from TGA curves as shown in Figure 7 only one step of the thermal decomposition was observed for the PU samples: in the unirradiated PU sample (0 kGy) the weight loss $94.78 \%$ occurs between 382.64 and $421.06^{\circ} \mathrm{C}$. For the irradiated PU samples which were irradiated with gamma radiation doses 50,100, and $150 \mathrm{kGy}$ the weight loss was 90.36 , 91.98 , and $91.66 \%$, respectively. This indicated the effect of radiation on crosslinking of polyurethane. The amount of carbonized residue (char yield) of these PUs in nitrogen atmosphere was more than $5 \%$ at $500^{\circ} \mathrm{C}$. The char yield of PU $(0 \mathrm{kGy})$ is higher than irradiated PU as seen in Figure 7. This means that the radiation crosslinking increases the thermal stability of PU.

According to the DTG curve (Figure 8) two steps of the thermal decomposition were observed for the unirradiated and irradiated PU samples: in the first step, the thermal decomposition was at $299.32,311.25,314.25$, and $318.35^{\circ} \mathrm{C}$ for $0,50,100$, and $150 \mathrm{kGy}$ and this could be attributed to the decomposition of PU soft segment. This indicated that gamma irradiation crosslinking clearly dominated in the soft segment in overall doses, where the crosslinking is believed to be most efficient in the soft phase [37]. The second thermal decomposition step $T_{\max }$ was at 408.07, 414.69, 411.99 , and $407.04^{\circ} \mathrm{C}$ for $0,50,100$, and $150 \mathrm{kGy}$, respectively. From the previous TGA/DTG curves the thermal stability of radiation crosslinking polyurethane is improved gradually, and, to achieve the best when the radiation dose was between $50 \mathrm{kGy}$ and $100 \mathrm{kGy}$, this can be attributed to the degree of crosslinking increased with the increase of radiation dose. However, when irradiation dose was $150 \mathrm{kGy}$, its thermal stability is worse than $50 \mathrm{kGy}$. Maybe if the irradiation dose was too high, the degradation reaction takes place, leading to the degree of crosslinking drop. The radiation crosslinking of polyurethane is preferred at radiation dose between $50 \mathrm{kGy}$ and $100 \mathrm{kGy}$, as it has the best degree of crosslinking and thus has the best heat resistance [38].

\section{Conclusion}

The FTIR results proved the prepolymerization of PU happened. The polymerization of urethane bond was proved by 


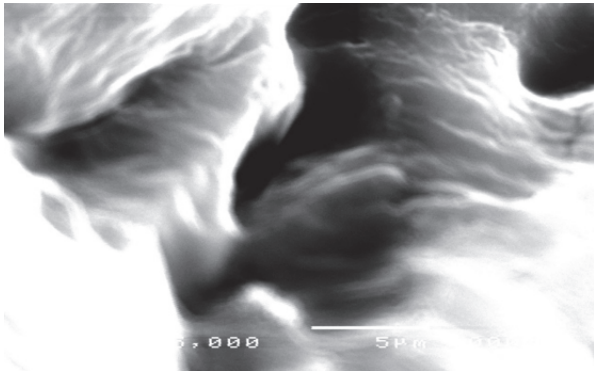

(a)

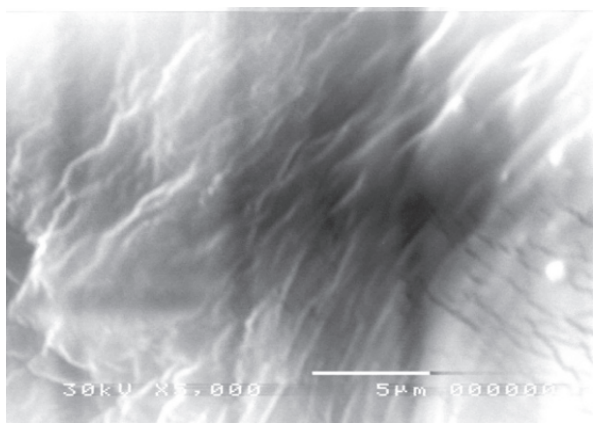

(b)

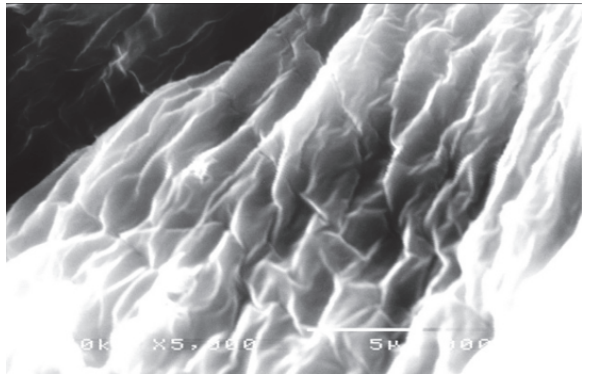

(c)

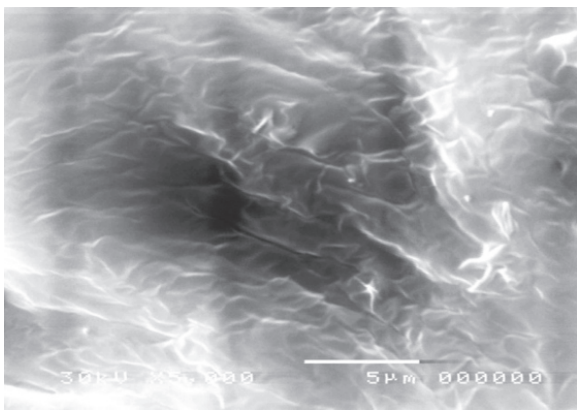

(d)

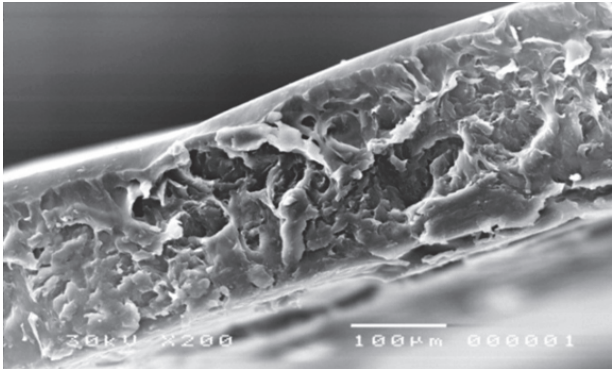

$\left(\mathrm{a}^{\prime}\right)$

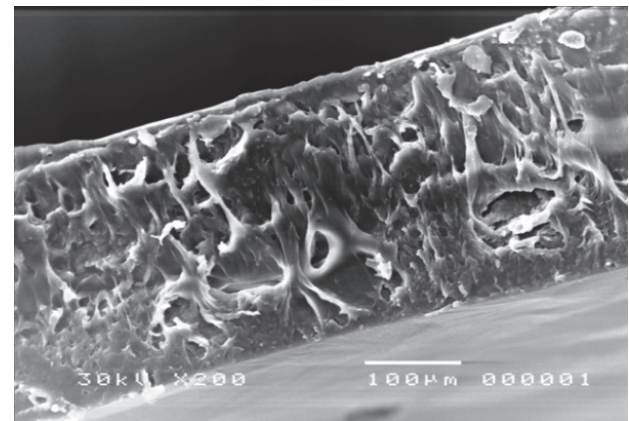

$\left(b^{\prime}\right)$

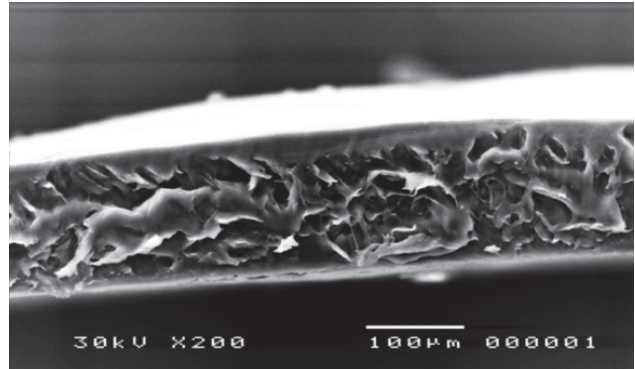

(c')

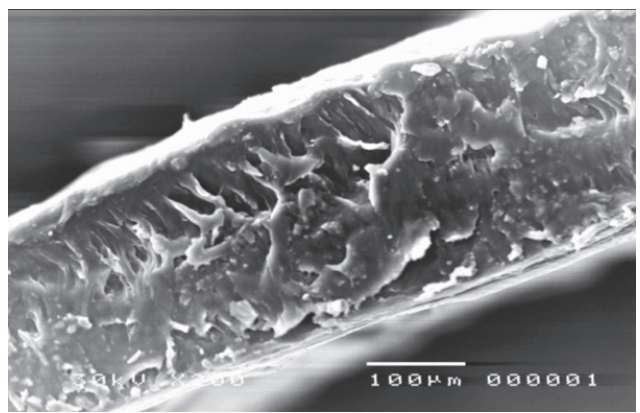

(d')

FIGURE 5: SEM of solid PU films after and before irradiated in absence of air: surfaces and cross-section of (a, a') 0 kGy, (b, b') 50 kGy, (c, c') $100 \mathrm{kGy}$, and $\left(\mathrm{d}, \mathrm{d}^{\prime}\right) 150 \mathrm{kGy}$.

the disappearance of the peak of isocyanate group around $2270-2250 \mathrm{~cm}^{-1}$. FTIR results proved that all isocyanates present in the prepolymer reactants and excess of $\mathrm{OH}$ form the rigid PU. Raman spectroscopy showed chemical bands characteristic of the molecular structure of polyurethanes, such as the urethane $(\mathrm{N}-\mathrm{H})$ amid II group $\left(1532 \mathrm{~cm}^{-1}\right)$ and phenol group $\left(1613 \mathrm{~cm}^{-1}\right)$. X-ray diffraction patterns showed that the degree of crystallinity is controlled by the gamma irradiation doses. The change of crystallinity can be explained by the degree of crosslinking of the PU samples based on radiation crosslinking of soft segments rather than hard segment. The polyurethane turned yellow after being irradiated in absence of oxygen under vacuum conditions. When unirradiated and irradiated PU samples are exposed to 


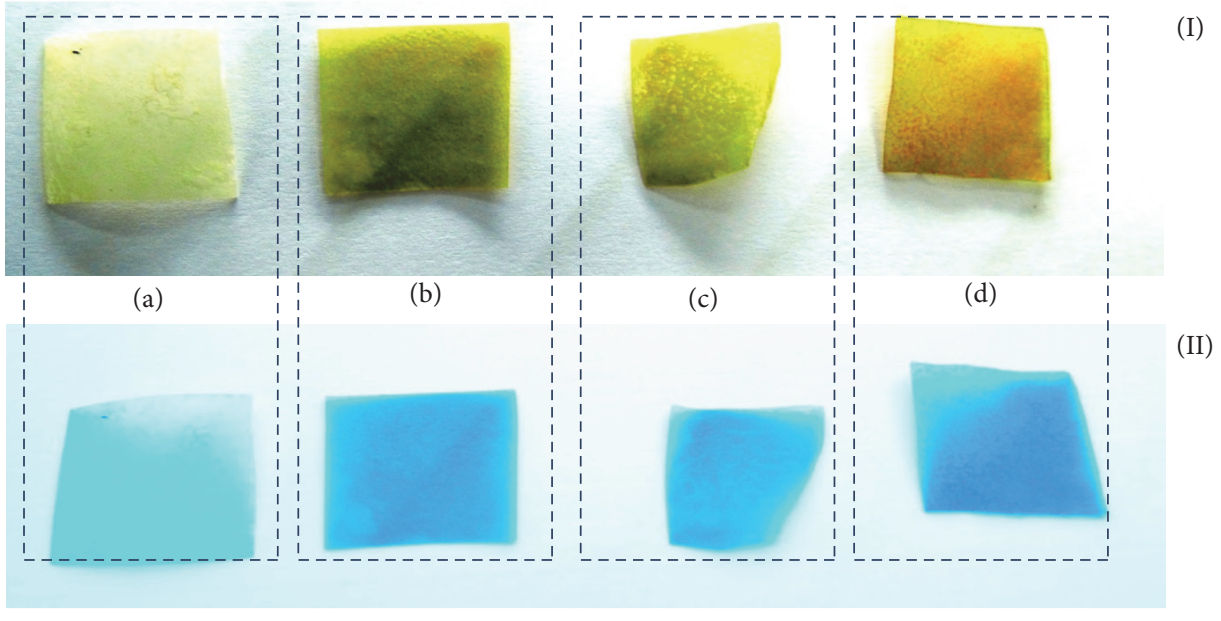

$\left(\mathrm{a}^{\prime}\right)$

(b')

(c)

(d')

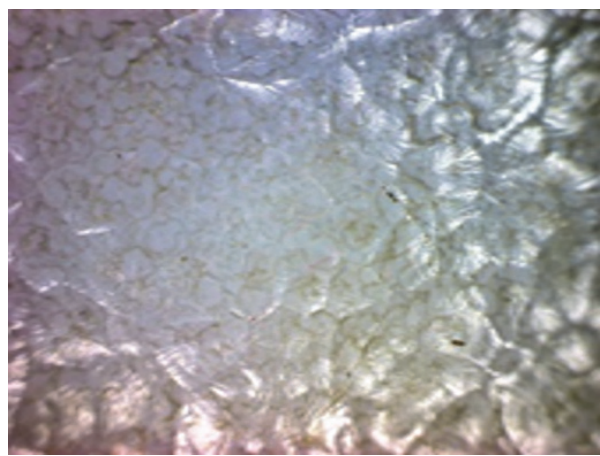

$\left(a^{\prime \prime}\right)$

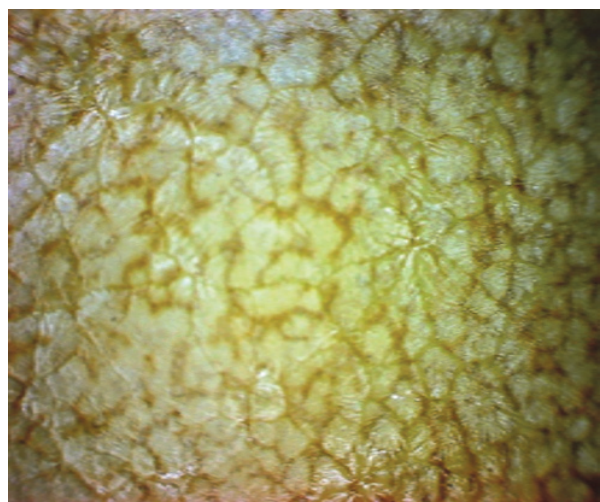

$\left(c^{\prime \prime}\right)$

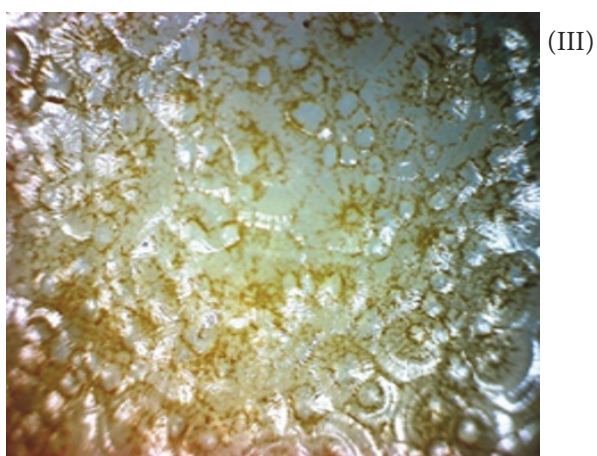

$\left(b^{\prime \prime}\right)$

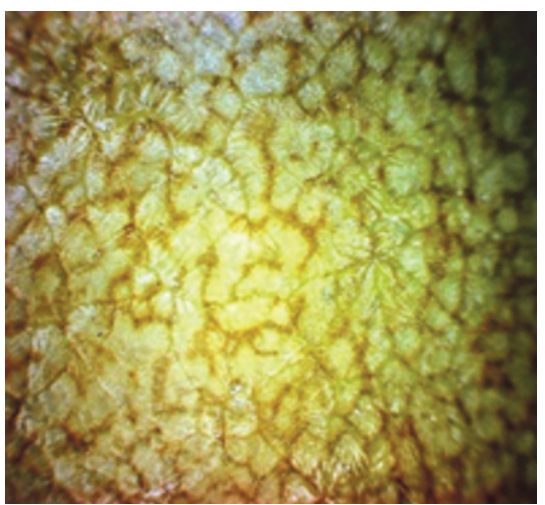

$\left(d^{\prime \prime}\right)$

FIGURE 6: The photo of PU sample was observed for irradiated polyurethane (a) $0 \mathrm{kGy}$, (b) $50 \mathrm{kGy}$, (c) $100 \mathrm{kGy}$, and (d) $150 \mathrm{kGy}$ (I) under visible light (II) under UV irradiation at $365 \mathrm{~nm}$ (III) Light photomicrographs (mag. 200x) of the irradiated polyurethane (a") $0 \mathrm{kGy}$, (b") $50 \mathrm{kGy},\left(\mathrm{c}^{\prime \prime}\right) 100 \mathrm{kGy}$, and (d") $150 \mathrm{kGy}$.

UV light $(362 \mathrm{~nm})$, it was found that the PUs emitted purple color where the intensity of color is increased for irradiated PU samples depending on the gamma radiation doses. This indicated that the irradiated PUs have conjugated structure and are capable of emitting fluorescence light. According to the DTG curve the gamma irradiation crosslinking clearly dominated in the soft segment in overall doses. TGA curves showed that the thermal stability is worse than $50 \mathrm{kGy}$. Maybe if the irradiation dose was too high, the degradation reaction takes place, leading to the degree of crosslinking drop. The radiation crosslinking of polyurethane is preferred at radiation dose between $50 \mathrm{kGy}$ and $100 \mathrm{kGy}$, as it has the best degree of crosslinking and thus has the best heat resistance. 


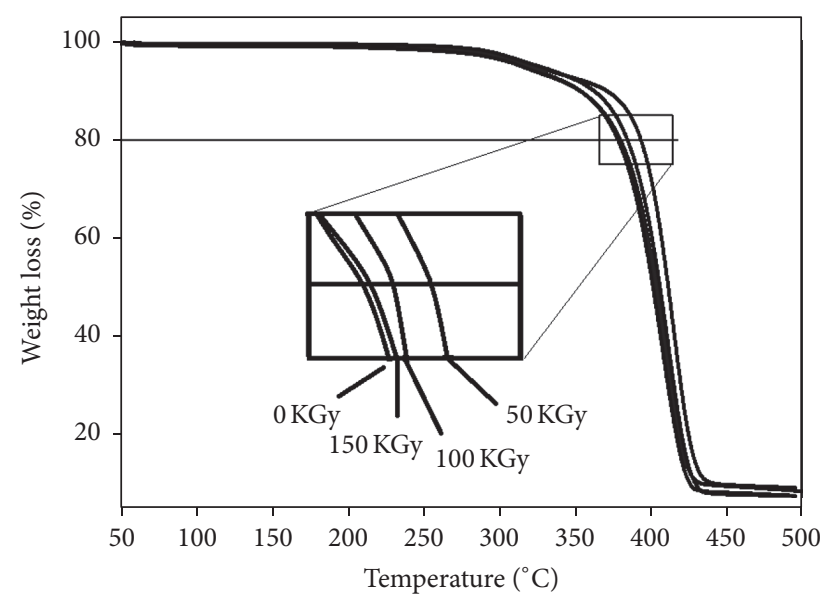

FIGURE 7: TGA curve of the irradiated polyurethane.

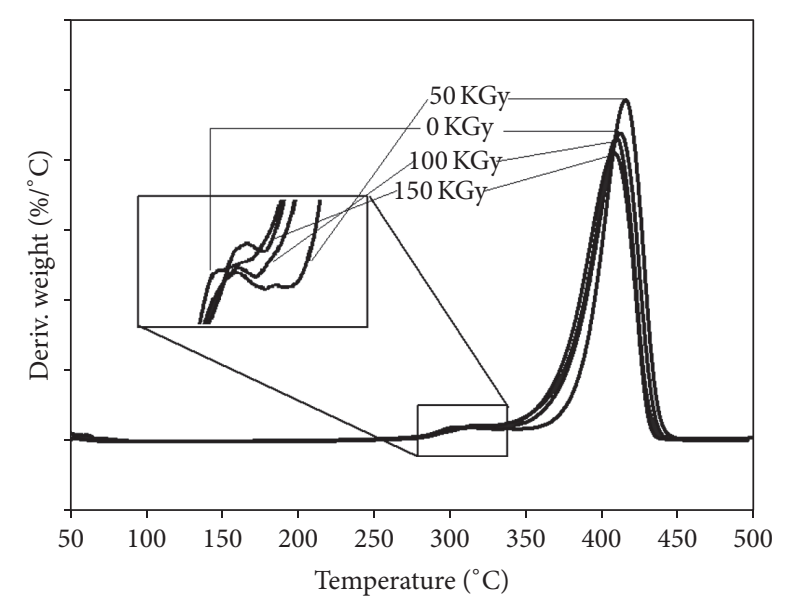

FIGURE 8: DTG curves for irradiated polyurethane.

\section{Competing Interests}

The authors declare that they have no competing interests.

\section{References}

[1] Z. S. Petrović, "Polyurethanes from vegetable oils," Polymer Reviews, vol. 48, no. 1, pp. 109-155, 2008.

[2] A. V. Raghu, G. S. Gadaginamath, N. T. Mathew, S. B. Halligudi, and T. M. Aminabhavi, "Synthesis and characterization of novel polyurethanes based on 4,4/-[1,4-phenylenedi-diazene-2,1diyl]bis(2-carboxyphenol) and 4,4I-[1,4-phenylenedi-diazene2,1-diyl]bis(2-chlorophenol) hard segments," Reactive and Functional Polymers, vol. 67, no. 6, pp. 503-514, 2007.

[3] A. V. Raghu and H. M. Jeong, "Synthesis, characterization of novel dihydrazide containing polyurethanes based on $N^{1}, N^{2}$ bis[(4-hydroxyphenyl)methylene] ethanedihydrazide and various diisocyanates," Journal of Applied Polymer Science, vol. 107, no. 5, pp. 3401-3407, 2008.

[4] H. M. Jeong, K. H. Jang, and K. Cho, "Properties of waterborne polyurethanes based on polycarbonate diol reinforced with organophilic clay," Journal of Macromolecular Science-Physics B, vol. 42, no. 6, pp. 1249-1263, 2003.
[5] S. H. Choi, D. H. Kim, A. V. Raghu et al., "Properties of graphene/waterborne polyurethane nanocomposites cast from colloidal dispersion mixtures," Journal of Macromolecular Science, Part B: Physics, vol. 51, no. 1, pp. 197-207, 2012.

[6] K. R. Reddy, A. V. Raghu, and H. M. Jeong, "Synthesis and characterization of novel polyurethanes based on 4,4'-1,4phenylenebis[methylylidenenitrilo]diphenol," Polymer Bulletin, vol. 60, no. 5, pp. 609-616, 2008.

[7] A. V. Raghu, G. S. Gadaginamath, S. S. Jawalkar, S. B. Halligudi, and T. M. Aminabhavi, "Synthesis, characterization, and molecular modeling studies of novel polyurethanes based on 2,2' -[ethane-1,2-diylbis(nitrilomethylylidene)]diphenol and 2,2' -[hexane-1,6-diylbis(nitrilomethylylidene)] diphenol hard segments," Journal of Polymer Science Part A: Polymer Chemistry, vol. 44, no. 20, pp. 6032-6046, 2006.

[8] A. V. Raghu, G. S. Gadaginamath, N. Mathew, S. B. Halligudi, and T. M. Aminabhavi, "Synthesis, characterization, and acoustic properties of new soluble polyurethanes based on 2,2' -[1,4-phenylenebis(nitrilomethylylidene)diphenol and 2,2' [4, $4^{\prime}$-methylene-di-2-methylphenylene-1,1' -bis(nitrilomethylylidene)]diphenol," Journal of Applied Polymer Science, vol. 106, no. 1, pp. 299-308, 2007.

[9] A. V. Raghu, G. Anita, Y. M. Barigaddi, G. S. Gadaginamath, and T. M. Aminabhavi, "Synthesis and characterization of novel polyurethanes based on 2,6-bis(4-hydroxybenzylidene) cyclohexanone hard segments," Journal of Applied Polymer Science, vol. 104, no. 1, pp. 81-88, 2007.

[10] K. R. Reddy, A. V. Raghu, H. M. Jeong, and Siddaramaiah, "Synthesis and characterization of pyridine-based polyurethanes," Designed Monomers and Polymers, vol. 12, no. 2, pp. 109-118, 2009.

[11] K. R. Reddy, K.-P. Lee, A. I. Gopalan, M. S. Kim, A. M. Showkat, and Y. C. Nho, "Synthesis of metal (Fe or Pd)/Alloy (Fe-Pd)-nanoparticles-embedded multiwall carbon nanotube/ sulfonated polyaniline composites by $\gamma$ irradiation," Journal of Polymer Science, Part A: Polymer Chemistry, vol. 44, no. 10, pp. 3355-3364, 2006.

[12] E. C. Azevedo, G. O. Chierice, S. C. Neto, D. S. Soboll, E. M. Nascimento, and C. M. Lepienski, "Gamma radiation effects on mechanical properties and morphology of a polyurethane derivate from castor oil," Radiation Effects and Defects in Solids, vol. 166, no. 3, pp. 208-214, 2011.

[13] S. Shin and S. Lee, "The influence of electron-beam irradiation on the chemical and the structural properties of medical-grade polyurethane," Journal of the Korean Physical Society, vol. 67, no. 1, pp. 71-75, 2015.

[14] E. C. Azevedo, E. M. Nascimento, G. O. Chierice, S. C. Neto, and C. M. Lepienski, "UV and gamma irradiation effects on surface properties of polyurethane derivate from castor oil," Polimeros, vol. 23, no. 3, pp. 305-311, 2013.

[15] C. Prisacariu, Polyurethane Elastomers: From Morphology to Mechanical Aspects, Springer, Vienna, Austria, 2011.

[16] E. Adem, E. Angulo-Cervera, A. González-Jiménez, J. L. Valentín, and A. Marcos-Fernández, "Effect of dose and temperature on the physical properties of an aliphatic thermoplastic polyurethane irradiated with an electron beam," Radiation Physics and Chemistry, vol. 112, pp. 61-70, 2015.

[17] Q. Tian, E. Takács, I. Krakovský, Z. E. Horváth, L. Rosta, and L. Almásy, "Study on the microstructure of polyester polyurethane irradiated in air and water," Polymers, vol. 7, no. 9, pp. 1755-1766, 2015. 
[18] O. I. H. Dimitry, Z. I. Abdeen, E. A. Ismail, and A. L. G. Saad, "Preparation and properties of elastomeric polyurethane/ organically modified montmorillonite nanocomposites," Journal of Polymer Research, vol. 17, no. 6, pp. 801-813, 2010.

[19] K. B. H. Badri, W. C. Sien, M. S. B. Raja Shahrom, L. C. Hao, N. Y. Baderuliksan, and N. R. Norzali, "FTIR spectroscopy analysis of the prepolymerization of palm-based polyurethane," Journal of Solid State Science and Technology, vol. 18, no. 2, pp. 1-8, 2010.

[20] D. P. Suhas, H. M. Jeong, T. M. Aminabhavi, and A. V. Raghu, "Preparation and characterization of novel polyurethanes containing 4,4'-\{oxy-1,4-diphenyl bis(nitromethylidine)\}diphenol schiff base diol," Polymer Engineering \& Science, vol. 54, no. 1, pp. 24-32, 2014.

[21] O. I. H. Dimitry, Z. Abdeen, E. A. Ismail, and A. L. G. Saad, "Studies of particle dispersion in elastomeric polyurethane/ organically modified montmorillonite nanocomposites," International Journal of Green Nanotechnology, vol. 3, no. 3, pp. 197212, 2011.

[22] G. A. Jeffrey and W. Saenger, Hydrogen Bonding in Biological Structures, Springer Science \& Business Media, Berlin, Germany, 1991.

[23] D. J. Lyman, "Polyurethanes. I. The solution polymerization of diisocyanates with ethylene glycol," Journal of Polymer Science, vol. 45, no. 145 , pp. 49-59, 1960.

[24] K. R. Reddy, A. V. Raghu, and H. M. Jeong, "Synthesis and characterization of novel polyurethanes based on $4,4^{\prime}$ - $\{1,4$-phenylenebis[methylylidenenitrilo]\}diphenol," Polymer Bulletin, vol. 60, no. 5, pp. 609-616, 2008.

[25] S. Parnell, K. Min, and M. Cakmak, "Kinetic studies of polyurethane polymerization with Raman spectroscopy," Polymer, vol. 44, no. 18, pp. 5137-5144, 2003.

[26] M. Cregut, M. Bedas, A. Assaf, M.-J. Durand-Thouand, and G. Thouand, "Applying Raman spectroscopy to the assessment of the biodegradation of industrial polyurethanes wastes," Environmental Science and Pollution Research, vol. 21, no. 16, pp. 9538-9544, 2014.

[27] M. M. Ghobashy and Z. I. Abdeen, "Influence of gamma irradiation on the change of the characterization of elastomeric polyurethane," Advanced Science, Engineering and Medicine, vol. 8, no. 9, pp. 736-739, 2016.

[28] G. Trovati, E. A. Sanches, S. C. Neto, Y. P. Mascarenhas, and G. O. Chierice, "Characterization of polyurethane resins by FTIR, TGA, and XRD," Journal of Applied Polymer Science, vol. 115, no. 1, pp. 263-268, 2010.

[29] J. H. Yang, B. C. Chun, Y.-C. Chung, and J. H. Cho, "Comparison of thermal/mechanical properties and shape memory effect of polyurethane block-copolymers with planar or bent shape of hard segment," Polymer, vol. 44, no. 11, pp. 3251-3258, 2003.

[30] K. M. Zia, I. A. Bhatti, M. Barikani, M. Zuber, and H. N. Bhatti, "XRD studies of polyurethane elastomers based on chitin/1, 4butane diol blends," Carbohydrate Polymers, vol. 76, no. 2, pp. 183-187, 2009.

[31] V. Kovacevic, L. J. Kljajie-Malinovic, I. Smit, M. Bravar, A. Agic, and Z. Cerovecki, "Adhesive composition systems in degradative conditions," in Adhesion 14, K. W. Allen, Ed., vol. 14, pp. 126-160, Springer, Berlin, Germany, 1990.

[32] C. Prisacariu, Polyurethane Elastomers: From Morphology to Mechanical Aspects, Springer Science \& Business Media, 2011.

[33] X. Wu, Y. Wu, C. Zhang et al., "Polyurethanes prepared from isocyanates containing triphenylamine derivatives: synthesis and optical, electrochemical, electrochromic and memory properties," RSC Advances, vol. 5, no. 72, pp. 58843-58853, 2015.
[34] H. C. Beachell and C. P. Son, "Color formation in polyurethanes," Journal of Applied Polymer Science, vol. 7, no. 6, pp. 2217-2237, 1963.

[35] K. Nassau, "Gamma-ray irradiation induced changes in color of tourmalines," American Mineralogist, vol. 60, no. 7-8, pp. 710713, 1975.

[36] A. V. Raghu, G. S. Gadaginamath, H. M. Jeong, N. T. Mathew, S. B. Halligudi, and T. M. Aminabhavi, "Synthesis and characterization of novel schiff base polyurethanes," Journal of Applied Polymer Science, vol. 113, no. 5, pp. 2747-2754, 2009.

[37] R. A. Assink, "Radiation crosslinking of polyurethanes," Journal of Applied Polymer Science, vol. 30, no. 6, pp. 2701-2705, 1985.

[38] C. Zhou, Bulk Preparation of Radiation Crosslinking Poly (Urethane-Imide), INTECH, 2012. 

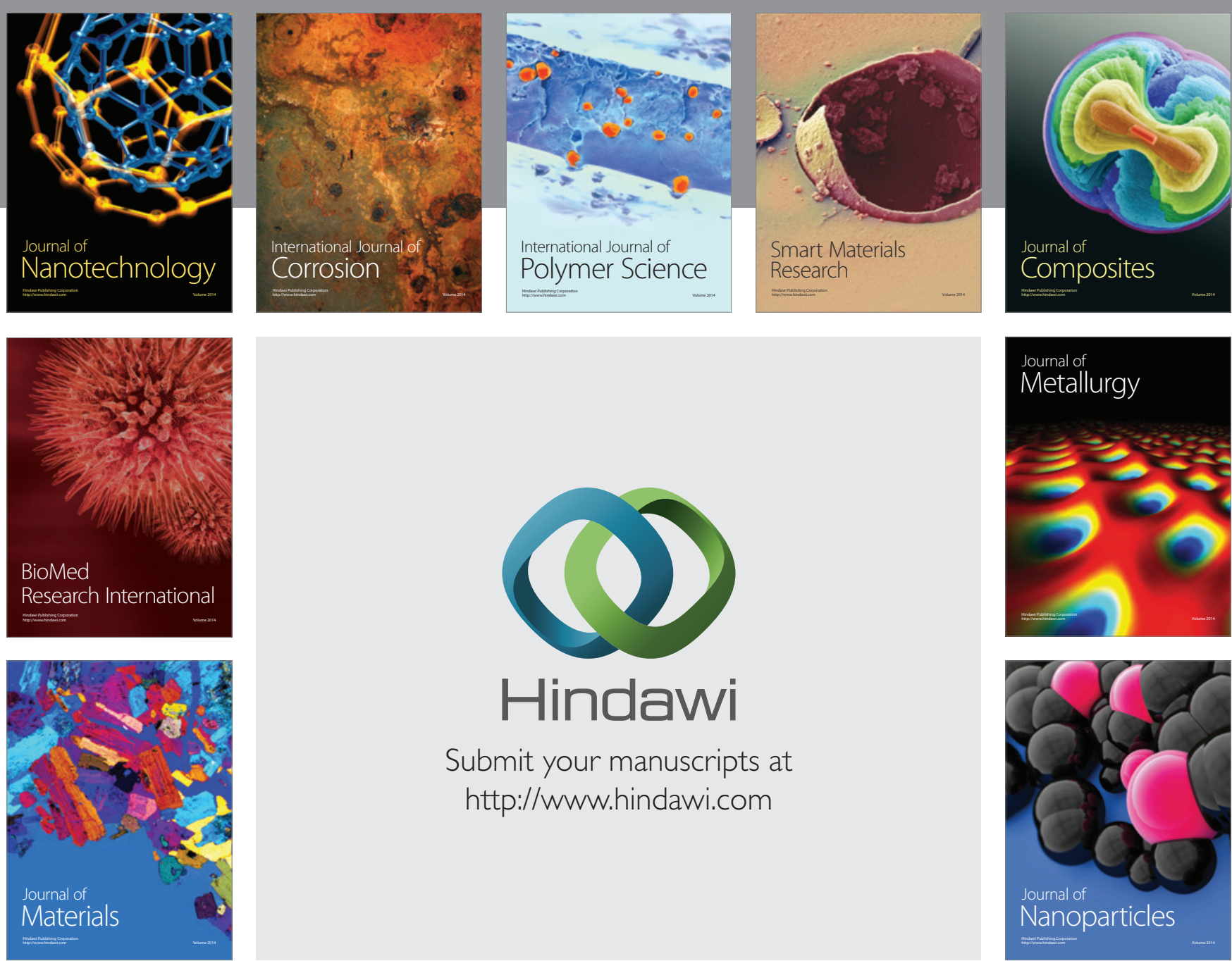

\section{Hindawi}

Submit your manuscripts at

http://www.hindawi.com

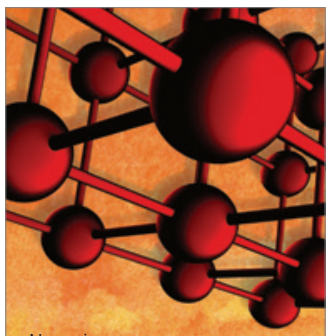

Materials Science and Engineering
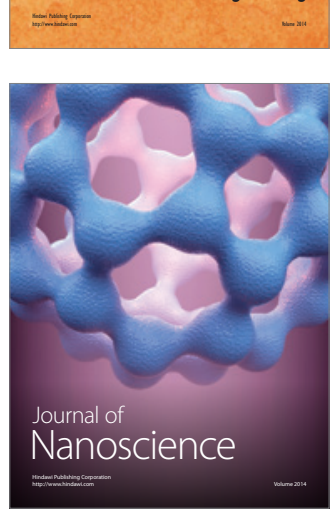
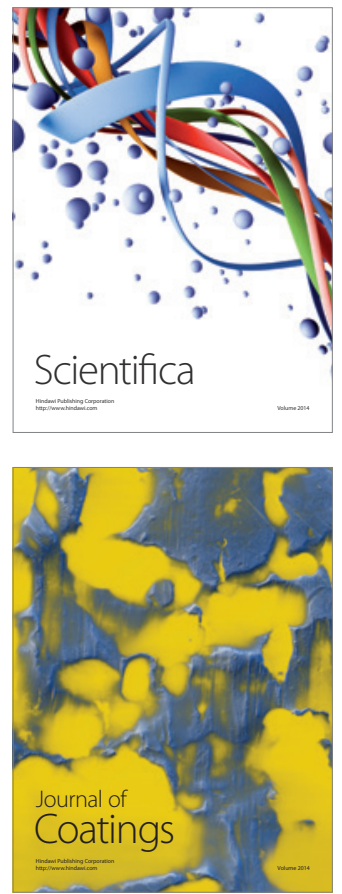
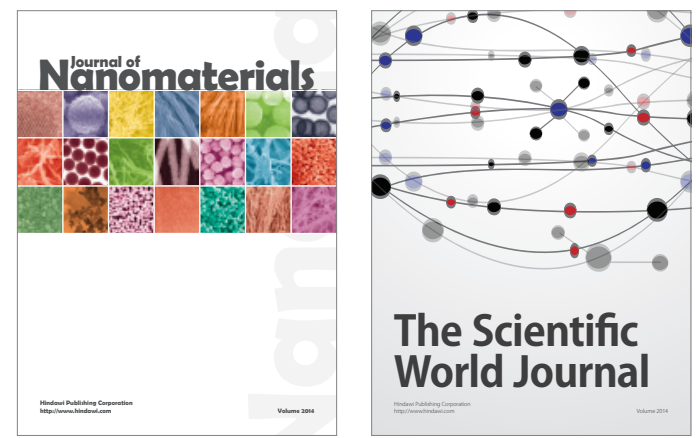

The Scientific World Journal
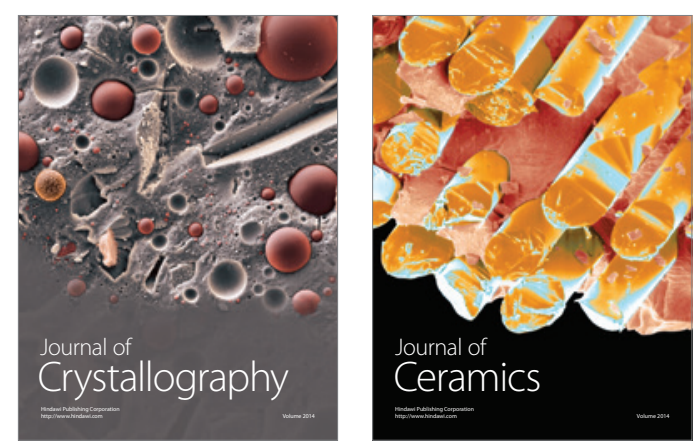
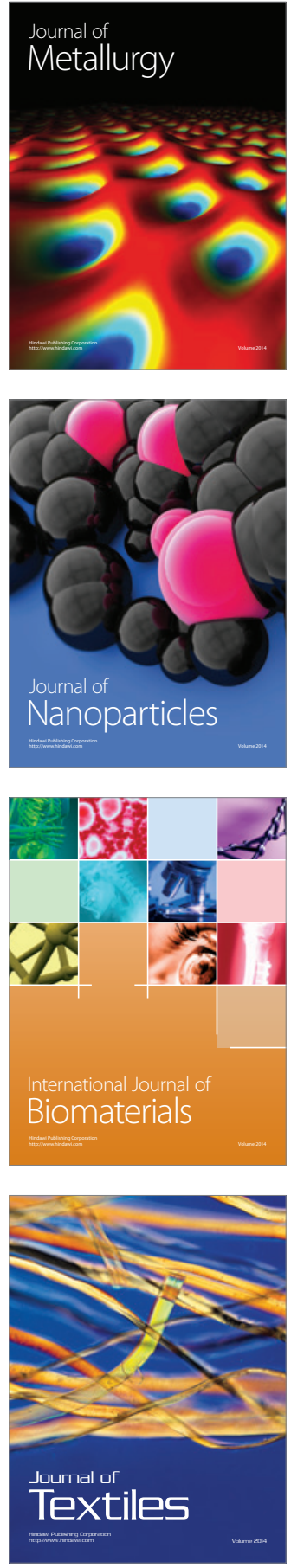